\title{
Osteoblastoma de la cuarta vértebra cervical
}

\author{
Osteoblastoma of the fourth cervical vertebrae \\ José Luis Alcocer Maldonado, ${ }^{*}$ Luis Gerardo Domínguez Carrillo ${ }^{\ddagger}$ \\ Citar como: Alcocer MJL, Domínguez CLG. Osteoblastoma de la cuarta vértebra cervical. Acta \\ Med GA. 2021; 19 (4): 562-563. https://dx.doi.org/10.35366/102548
}

Femenino de 35 años de edad, ama de casa sin antecedentes de importancia, con padecimiento de tres semanas de evolución caracterizado por dolor cervical incapacitante, progresivo, que le impide conciliar el sueño. A la exploración: contractura de músculos de nuca, incapacidad para la flexión y extensión del cuello; exploración neurológica normal, fuerza muscular, sensibilidad y reflejos en las cuatro extremidades normales. Se practica resonancia magnética (Figura 1A) y tomografía de la columna cervical (Figura 1B-C), se encuentra masa tumoral que afecta la lámina de la cuarta vértebra cervical. Se intervino quirúrgicamente por laminectomía practicando la resección de la totalidad
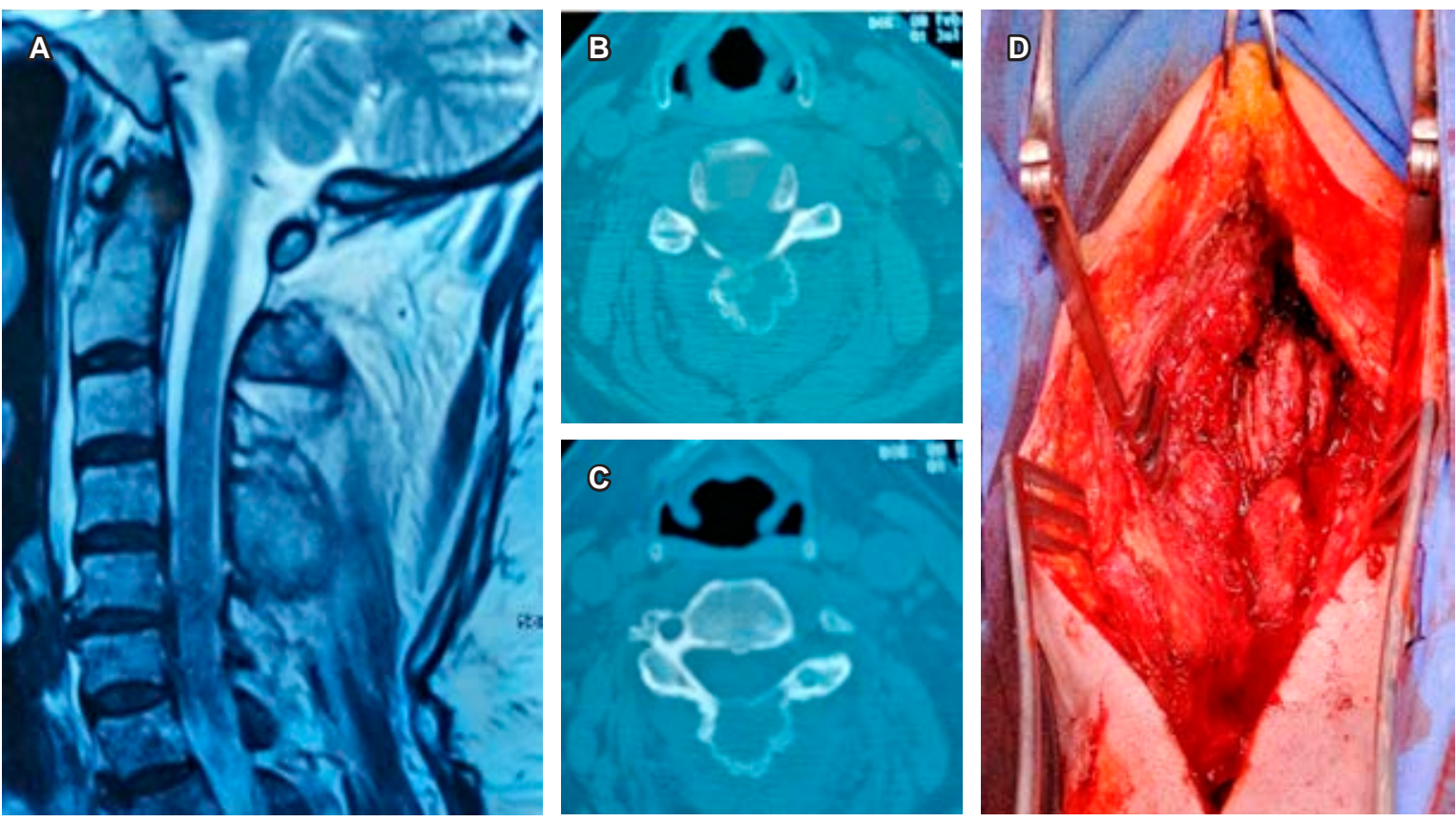

Figura 1: A) Resonancia magnética de columna cervical en corte sagital ponderado en T2 que muestra lesión tumoral en arco posterior de la cuarta vértebra. B y C) Tomografía computarizada en cortes axiales a nivel de C4, mostrando lesión lítica expansiva, con calcificaciones internas y bordes de esclerosis reactiva. D) Procedimiento quirúrgico antes de laminectomía con escisión radical de lesión ósea tumoral.

\footnotetext{
* Neurocirujano. División de Cirugía del Hospital Angeles León. León, Guanajuato. México.

* Especialista en Medicina de Rehabilitación. Catedrático de la Facultad de Medicina de León, Universidad de Guanajuato. México.
}
Correspondencia:
Dr. Luis Gerardo Domínguez Carrillo
Correo electrónico: Igdominguez@hotmail.com
Aceptado: 02-08-2020. 
de la lesión (Figura 1D), el reporte histopatológico fue de osteoblastoma.

Los osteoblastomas son tumores raros formadores de hueso que pueden ser localmente agresivos. Son de 1.5-2 $\mathrm{cm}$ o mayores y tienden a afectar el esqueleto axial con mayor frecuencia que el osteoma osteoide. Representan de 1 a 3\% de todos los tumores óseos primarios. Los pacientes suelen presentarlos alrededor de la segunda a la tercera década de la vida. La relación de sexo es de 2.5:1 a favor del masculino. ${ }^{1}$ Clínicamente se manifiestan en columna, con inicio insidioso de dolor, de incremento nocturno con una respuesta mínima a los salicilatos (sólo 7\% de los pacientes responden, a diferencia del osteoma osteoide). A la exploración, el área donde se encuentra es sensible, con disminución importante de ángulos de movimiento. En cuanto a su localización se observan en columna vertebral en aproximadamente $40 \%$, involucrando principalmente a los elementos vertebrales posteriores, en columna cervical se encuentran entre 9 y $39 \%$ de todas las lesiones espinales, en el sacro ocupan el $17 \% .^{2}$ Radiológicamente las lesiones son predominantemente líticas y tienden a ser expansivos, con bordes de esclerosis reactiva o periostitis, hasta en $50 \%$ de los casos pueden presentar calcificación interna, la mineralización interna de la matriz se aprecia mejor en la tomografía computarizada. Las imágenes de resonancia magnética suelen ser inespecíficas y pueden sobreestimar la lesión; la cintigrafía muestra captación intensa, lo que es típico de todas las lesiones que exhiben un aumento en el recambio óseo. ${ }^{3}$ La escisión quirúrgica radical es a menudo el tratamiento de elección. ${ }^{4}$ El diagnóstico diferencial del osteoblastoma cuando se presente en columna debe efectuarse con quiste óseo aneurismático y tuberculosis. Histológicamente el osteoblastoma es similar al osteoma osteoide, pero de mayor volumen, son formadores de hueso y osteoide y están compuestos por osteoblastos, y presentan una alta vascularización asociada; ocasionalmente tienen carácter agresivo (maligno), caracterizado por un alto número de osteoblastos con atipia nuclear.

\section{REFERENCIAS}

1. Berry M, Mankin H, Gebhardt M, Rosenberg A, Hornicek F. Osteoblastoma: a 30-year study of 99 cases. J Surg Oncol. 2008; 98 (3): 179-183.

2. Yin H, Zhou W, Yu H, Li B, Zhang D, Wu Z et al. Clinical characteristics and treatment options for two types of osteoblastoma in the mobile spine: a retrospective study of 32 cases and outcomes. Eur Spine J. 2014; 23 (2): 411-416.

3. Yalcinkaya U, Doganavsargil B, Sezak M, Kececi B, Argin M, Basdemir $G$ et al. Clinical and morphological characteristics of osteoid osteoma and osteoblastoma: a retrospective single-center analysis of 204 patients. Ann Diagn Pathol. 2014; 18 (6): 319-325.

4. Kadhim M, Binitie O, O'Toole P, Grigoriou E, De Mattos CB, Dormans JP. Surgical resection of osteoid osteoma and osteoblastoma of the spine. J Pediatric Orthop. 2017; 26: 362-368. 